\title{
Enabling disabled participation in sport: Roadrunning
}

\author{
D Maralack, PhD \\ School of Management Studies, University of Cape Town, South Africa
}

Corresponding author: D Maralack (David.maralack@uct.ac.za)

The Old Mutual Two Oceans Marathon (OMTOM) and Comrades Marathon were challenged by wheelchair participants to enter their ultramarathon races in 2016, despite the ultramarathon being physically challenging over $56 \mathrm{~km}$ and $90 \mathrm{~km}$ respectively. The terrain for both is mountainous, exacerbating the physical challenge of the distance. Initially both events declined entry to two wheelchair participants, based on procedural, logistical and safety grounds, prompting social media protests and debate. This commentary focuses in brief on the two sides of the same coin: the rights of disabled and specifically wheelchair athletes to be included in ultramarathons in South Africa; and the management and regulatory responsibilities of event organisers in these complex events.

Keywords: running events; mass participation; inclusion; wheelchair; Two Oceans Marathon

S Afr J Sports Med 2016;28(2):59-60.DOI: 10.17159/2078-516X/2016/v28i2a1429

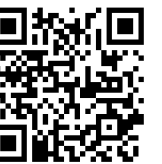

In March and May 2016, the Old Mutual Two Oceans Marathon (OMTOM) and Comrades Marathon were challenged by wheelchair participants to enter their ultramarathon races. The ultramarathons are physically challenging, pushing athletes to their limits over $56 \mathrm{~km}$ and $90 \mathrm{~km}$ respectively, over mountainous terrain, exacerbating the physical challenge of the distance.

Initially both events declined entry to two wheelchair participants based on procedural, logistical and safety grounds, prompting vitriolic discussions on the social media. Contestation developed around the ways in which disabled sport participants are integrated (or not) into sporting events with the management, logistics and operational challenges that confront event organisers.

This commentary focuses briefly on what can be considered as two sides of the same coin: the rights of disabled and particularly wheelchair participants to be included in ultramarathons in South Africa; and the management and regulatory responsibilities of the event organisers in these complex mass participation events.

\section{Contestations}

In the social media, proponents argued that it is the constitutional right for differently abled athletes to be permitted to participate in any event. Event organisers were branded as "anti-disabled", "lazy" and "intransigent". This strand of argument predominated, although some commentators argued that an ultramarathon was not appropriate as "it is too hard" and "physically too challenging".

In clarifying the issues it is important to examine the rights and responsibilities of differently abled participants, as well as those of the event/race organisers. Race organisers are required to work within a human rights culture and simultaneously comply with a myriad of safety, health and environmental procedures and regulations.

\section{Benchmarking the issues}

While South Africa still grapples with managing the incorporation of disabled athletes into mainstream events, other countries have well developed policies and procedures. In this commentary there is a brief reflection on policies of England Athletics (EA) and Road Runners Club of America (RRCA) on disabled athletic participation, as well as the key policy, health, safety, procedural and monitoring considerations that need to be taken into account in South African roadrunning.

The EA and RRCA have well developed disabled inclusion policies and processes. An important starting point for both is their focus on facilitating participation by athletes with disabilities. The EA Inclusion Policy ${ }^{1}$ argues that disabled people participate in athletic events for the same reason as all athletes - for enjoyment, to improve fitness, and to experience the challenge and achievement of competition. As the governing body, EA enhances the knowledge and confidence of event organisers in promoting the inclusion of disabled athletes in events, fosters a change in attitudes, and improves opportunities for disabled athletes to participate. This occurs while safeguarding the safety of all athletes.

Similarly, the RRCA ${ }^{2}$ argue that while participant safety in a running event remains the paramount concern of any event organiser, clear guidelines will help event organisers focus on real safety concerns related to a specific disability and "not concerns based on false perceptions, stereotypes or generalizations about athletes with disabilities". Hence, the RRCA's policy guidelines assist race organisers to deal with the complex questions surrounding disabled athlete participation in general, including those in wheelchairs. They stress that the guidelines are not intended to cover all events or situations, but rather to foster discussions among event directors, members of the disabled community, law enforcement, public safety personnel and others involved with a particular event.

The governing bodies of the EA and RRCA respectively predicate entry for disabled athletes on an accommodation request based on, for example, the Policy on Americans with Disability Act, ${ }^{2}$ which includes: a request for accommodation for a specific event which needs to be made to a race organiser a minimum of four to six weeks prior to an event. Also, event organisers are encouraged to have a space on their entry forms requesting whether disability accommodation is needed, and informing athletes that it takes four to six weeks after receipt of all medical documents to evaluate such a request. It remains the responsibility of the applicant to contact the race director to ensure compliance with event requirements.

They highlight that operationally it may not be reasonable to make an adjustment for disabled athletes; however, it is the race organiser's responsibility to ensure that they have taken all reasonable steps to consider and implement any 
reasonable adjustments that could be made.

\section{South Africa}

These are useful considerations for enabling differently abled participation in roadrunning in South Africa. The South African National Sport and Recreation Plan (NSRP) ${ }^{3}$ emphasises inclusion, directing all sports organisations to develop clear and consistent processes for the inclusion of all participants. At present, policies do promote participation by disabled (including wheelchair) participation in road races, but the guidelines for implementation and accommodation are left to the event organisers.

Similar to USA Track \& Field (USATF) and EA above, in South Africa participant rights have to be balanced with requirements contained in the "Safety at Sports and Recreational Events Act" (SASREA) ${ }^{4}$. SASREA sets minimum safety and security standards to safeguard the well-being of all persons at events; holds event role players to account and regulates safety certificates and public liability at events. The Act requires that event organisers have approved safety and security measures in place and that its implementation is managed by appropriately experienced people.

Translating the requirements of SASREA in South Africa, road races have to specifically consider how to deal with barriers to participation, and receive prior events planning approval for: (1) traffic and wide bay parking access at the start and finish of the event; (2) appropriate safety logistics at course entry and start position; (3) sufficient course width to accommodate wheelchairs on the route and to consider alternatives when space is deemed to be insufficient; (4) special course considerations such as speed humps, steep hills, descents, and to identify mitigation measures; (5) on course access for medical vehicles that can transport wheelchairs; (6) toilet facilities at the start, en route and at the finish that are accessible for wheelchairs. Over and above these legal requirements, drivers of traffic and safety vehicles, volunteers and event staff are required to attend special briefings on all processes and mitigation measures that are in place.

The Old Mutual Two Oceans Marathon therefore has to comply with these requirements and some challenges are the congested start, access and egress on the narrow stretches of shared road with cars on fifty per cent of the course, the steep inclines and, in particular, the descents on Chapman's Peak and Constantia Nek. In addition, race organisers are required to ensure that the medical infrastructure and services en route can respond to all demands. This is not as simple as it seems.

\section{Going forward - What is to be done?}

An important starting point for all stakeholders is to remove barriers to participation of disabled athletes and at the same time ensuring the safety of all runners. In South Africa this requires collaboration and joined-up policymaking and implementation between the governing body of Athletics South Africa (ASA), its provincial affiliates, race organisers, disability sport governing bodies, participants and public safety officials. Clear national policy guidelines by ASA will assist race organisers to deal with the complex questions surrounding disabled athlete participation, including those for wheelchairs.

It is important to acknowledge that event owners have legal responsibilities but it is also imperative to provide a welcoming environment, starting with examining ways in which disabled people can participate as opposed to focusing on the barriers to participation. Race organisers need to encourage communication in order to ensure application for event approval is made timeously and enable race organisers to comply with safety procedures specific to wheelchairs. Inviting key stakeholders such as the Western Province Sport Association for Physically Disabled (WPSAPD) in Cape Town, South Africa, to become a stakeholder in decision-making, ensures that experts guide the process, monitor application and provide feedback for improvement.

Disabled athletes should be encouraged to contact the race organiser and governing body in advance to discuss the needs and requirements to facilitate inclusion. Considerations would include requirements stipulated in SASREA, such as access, health, safety, traffic, medical clearance, safety of equipment, so that there is no danger to either the participants or environment. It is acknowledged that in certain instances it may be inappropriate to permit disabled participation, especially if an unreasonable or drastic adjustment is required that will change the nature of the event. If a risk assessment for the event indicates that it may be unsafe for disabled participation, then the risk assessor must be able to show that the decision was based on sufficient knowledge in the area of disability or has consulted with the appropriate disability organisation ${ }^{2}$.

\section{Conclusion}

This debate needs to be engaged with and understood in the broader running community. All athletes are entitled to enter a race under the same risks and to challenge themselves with hard physical effort, in adverse weather and course conditions. However, there is currently no joined-up policy providing clear and consistent processes of inclusion and circumstances for exclusion.

\section{Notes:}

1. USA Track and Field is the governing body for athletics in USA. The Road Runners Club of America is affiliated to USAT\&F and aligns with national USAT\&F policy and regulations.

2. OMTOM has redesigned their online application form to include an indication of type and degree of disability, public indemnity process and specific timelines for approval.

\section{References}

1. England Athletics. Inclusive Athletics Guidance: A resource to help athletics providers increase participation by disabled people. Accessed http://www.englandathletics.org/disability-athletics/resources August 15, 2016.

2. Road Runners Club of America. Guidelines to facilitate participation by athletes with disabilities. Accessed in http://www.rrca.org/resources/eventdirectors/guidelines-for-safe-events/challenged-athletes, August 15, 2016.

3. Sport and Recreation South Africa. National Sport and Recreation Plan Pretoria: Government Printers. 2012.

4. Sport and Recreation South Africa. Safety at Sports and Recreational Events Act, 2009. Pretoria: Government Printers. 2010. 